\title{
LUTA PELA TERRA E COBERTURA JORNALÍSTICA: UM ESTUDO DE CASO DO JORNAL GAZETA DO POVO
}

\author{
Fight for the land and journalistic coverage: a case study of the Gazeta do Povo \\ newspaper
}

\section{Lucha por la tierra y cobertura periodista: un estudio de caso del periódico Gazeta do Povo}

Carla Candida Rizzotto Doutora em Comunicação. Professora e pesquisadora (PPGCOM/UFPR). carla_rizzotto@yahoo.com.br

Diego Antonelli Mestre em Comunicação (PPGCOM/UFPR). diego-antonelli@bol.com.br

\section{Resumo}

Esta pesquisa tem como objetivo comparar a cobertura jornalística da Gazeta do Povo nas questões e conflitos envolvendo a luta pela terra em três diferentes episódios da história do Paraná: Guerrilha de Porecatu (1947-1951), Levante dos Posseiros de 1957 e Movimento dos Trabalhadores Rurais Sem Terra (1998). Para alcançar o presente objetivo serão utilizados os arcabouços preconizados pela teoria construtivista, que entende que a produção de notícias é uma das formas de "construção social da realidade", ou seja, que a mídia possui condições de criar ou gerar uma realidade social mediante a prática jornalística (Tuchman, 1983, 1993, 2002; Alsina, 2009; Berger e Luckman, 2002). Tal estudo visa fornecer elementos que apontem como se deu a evolução histórica da cobertura jornalística sobre estes assuntos, demonstrando como esse tema foi "construído" pelo jornal no decorrer das décadas.

Palavras-chave: Construção social da realidade. Lutas pela terra. Gazeta do Povo.

\begin{abstract}
This research aims to compare the journalistic coverage of the Gazeta do Povo in the issues and conflicts involving the struggle for land in three different episodes in the history of Paraná: Porecatu Guerrilla (1947-1951), Rise of the Squatters of 1957 and the Landless Rural Workers' Movement (1998). In order to reach the present objective, the frameworks proposed by the constructivist theory will be used, which understands that the production of news is one of the forms of "social construction of reality", that is, that the media can create or generate a social reality through journalistic practice (Tuchman, 1983, 1993, 2002, Alsina, 2009, Berger and Luckman, 2002). This study aims to provide elements that point out the historic evolution of journalistic coverage on these subjects, demonstrating how this theme was "built" by the newspaper over the decades.
\end{abstract}

Key words: Social construction of reality. Struggle for land. Gazeta do povo. 


\section{Resumen}

Esta investigación tiene como objetivo comparar la cobertura periodística de la Gazeta de Povo en las cuestiones y conflictos involucrando la lucha por la tierra en tres diferentes episodios de la historia del Paraná: Guerrilla de Porecatu (1947-1951), Levante de los Posseiros de 1957 y Movimiento de los Trabajadores Rurales Sin Tierra (1998). Para alcanzar el presente objetivo serán utilizados los armazones preconizados por la teoría constructivista, que entiende que la producción de noticias es una de las formas de "construcción social de la realidad", o sea, que los medios tienen condiciones de crear o generar una realidad social mediante la práctica periodística (Tuchman, 1983, 1993, 2002; Alsina, 2009, Berger у Luckman, 2002). Este estudio pretende proporcionar elementos que apunten como se dio la evolución histórica de la cobertura periodística sobre estos asuntos, demostrando cómo ese tema fue "construido" por el periódico a lo largo de las décadas.

Palabras clave: Construcción social de la realidad. Lucha por la tierra. Gazeta do Povo.

\section{INTRODUÇÃO}

Em pelo menos três momentos ao longo da história do século XX o Paraná foi palco de conflitos e mortes envolvendo a luta pela terra: Guerrilha de Porecatu (1947-1951), Levante dos Posseiros de 1957 e Movimento dos Trabalhadores Rurais Sem-Terra ${ }^{1}$ considerados os mais significativos da história do estado do Paraná. Coube aos meios de comunicação a missão de tornar público tais eventos que ocorriam no interior do estado. Um desses veículos foi o periódico Gazeta do Povo, em circulação desde 1919. A Gazeta do Povo, fundada no dia 3 de fevereiro de 1919, figurou, em 2015, segundo a Associação Nacional dos Jornais, como o periódico de maior circulação do Paraná com mais de 36,3 mil exemplares impressos. Em 2017, o veículo passou a circular em edição diária on-line e uma edição impressa semanal. O periódico também possui relevância histórica, já que se mantém na ativa ininterruptamente há um século.

A proposta deste artigo é a de analisar a cobertura noticiosa do jornal paranaense Gazeta do Povo acerca dos três episódios citados. Assim, será possível perceber de que maneiras as perspectivas jornalísticas foram se alterando no decorrer das décadas. Como escrevem Ribeiro e Brasiliense (2007, p.222), os meios de comunicação "são hoje os principais atores na realização do trabalho de enquadramento dos acontecimentos do presente e também do passado das coletividades. É através deles que se realiza a operação da memória sobre os acontecimentos e as interpretações que se quer salvaguardar”.

1 Optamos por analisar a cobertura jornalística do ano de 1998, por se tratar do ano em que foram contabilizadas mais mortes nos campos paranaenses. 
Para atingir os objetivos propostos a teoria construtivista será utilizada como referencial teórico. Segundo essa corrente, a atividade jornalística apresenta-se como um dos pilares da construção do cotidiano (TUCHMAN, 1983, 1993, 2002; ALSINA, 2009; BERGER, LUCKMAN, 2014). Para compreender como as notícias abordam as relações conflituosas entre poder político e movimentos sociais torna-se imprescindível discutir os passos da produção jornalística. Esse processo recai em analisar como a engrenagem das estruturas e hierarquias dos meios de comunicação implicam nas rotinas produtivas e como devem ser debatidos os critérios de noticiabilidade, as rotinas de produção, fontes jornalísticas e o mito da objetividade. É nessa perspectiva que se pauta a teoria construtivista, afinal, "os jornalistas são, como todo o mundo, construtores da realidade ao seu redor. Mas também conferem estilo narrativo a essa realidade, e, divulgando-a, tornam-na uma realidade pública sobre o dia-a-dia" (ALSINA, 2009, p. 11). A notícia, como expressa Alsina, é uma representação da realidade, que é gerada institucionalmente e que se manifesta inserida na construção de um mundo possível.

Conforme aponta a teoria, é a mídia que torna os fatos visíveis e aproxima os cidadãos dos acontecimentos: "O que não aparece na mídia não existe para muita gente" (ALSINA, 2009, p.129). Alsina afirma ainda que o processo de construção social da realidade depende também diretamente da prática produtiva do jornalismo, afinal, a mídia também é responsável por criar e reproduzir a realidade social. Da mesma maneira, Tuchman $(1983$, p.16) aponta que a notícia é, por si, um método institucional para fazer com que a informação esteja disponível aos consumidores.

La noticia es localizada, recogida y diseminada por profesionales que trabajan em organizaciones (...), um produto de los informadores que actúan dentro de procesos institucionales y de conformidad con prácticas institucionales. Esas prácticas incluyen necessariamente la asociación com instituciones cuyas noticias son informadas de manera rutinaria.

No processo rotineiro de produção da notícia são adotadas estratégias que recaem na própria apresentação da notícia (ALSINA, 2009; TUCHMAN, 1983). Para exemplificar é possível apontar o fato de que a fonte jornalística deve ser devidamente citada, as aspas devem ser utilizadas para denotar a afirmação de determinada pessoa, torna-se necessário utilizar e publicar os dados e documentos para comprovar o que está sendo redigido, isolar o espaço opinativo do informativo, entre outros.

Assim, filiado a tal base teórica, este artigo está assim dividido: em primeiro lugar apresentamos o método de coleta de dados, o corpus de análise e o método de análise das 
notícias. Em seguida, apresentamos e discutimos os resultados em três seções, sendo uma para cada um dos movimentos por terra citados nesta introdução. Optamos por apresentar os dados de forma intercalada com o referencial teórico que nos dá apoio. Por último, nas considerações finais buscamos traçar as comparações entre a cobertura dos três períodos históricos.

\section{MATERIAL E MÉTODOS}

A partir das premissas teóricas e da contextualização histórica dos movimentos sociais analisados, busca-se apontar - em cada movimento - como a Gazeta do Povo priorizou e construiu tais episódios históricos. Para tanto, foram analisadas as reportagens publicadas pelo periódico nos referidos anos a partir do acervo mantido pela Biblioteca Pública do Paraná. Foram encontradas 29 reportagens publicadas pela Gazeta do Povo sobre a Guerrilha de Porecatu, em 1951; 52 a respeito do Levante de 1957 e 213 reportagens acerca do MST em $1998^{2}$.

Para interpretação dos dados foi utilizada a análise de enquadramento, que, de acordo com Carvalho (2009), é esclarecedora para compreender que durante o processo de construção das narrativas jornalísticas, são acionados diferentes quadros de referência utilizados para dar inteligibilidade ao que é noticiado. Sob este mesmo prisma Antunes (2009, p.96) ressalta que existe uma clara proposição de que "a construção jornalística da notícia se dá no escopo de enquadramentos, que se fazem presentes na matéria e ajudam a compor seu processo de significação e instigam o leitor a perceber a realidade de maneira similar”. Assim, o frame torna-se um objeto que oferece ao leitor elementos para a compreensão da notícia e irá influenciar no processo de construção social da realidade.

Como indícios dos enquadramentos, este artigo pautou-se nas fontes, na seleção lexical e na seleção noticiosa com base nos critérios de noticiabilidade. Deste modo, foi possível observar, por exemplo, se houve a predominância de fontes oficiais e como os integrantes dos movimentos sociais foram ouvidos e, consequentemente, retratados pelo jornal. Além disso, a análise também procurou mostrar como se deu a utilização das frases dos entrevistados (ou das aspas, como afirma Tuchman) no processo de construção das reportagens. Outro ponto averiguado foi a seleção das palavras utilizadas para compor as

2 Este é o ano apontado como o de maior número de mortes envolvendo integrantes do MST. Oito integrantes do movimento, segundo a Comissão da Pastoral da Terra, foram assassinados no estado no referido período. 
reportagens. Isso porque a utilização de alguns termos pode soar como elogiosa ou crítica ao tema retratado na matéria e, de tal forma, ajuda a entender como este assunto foi abordado pelo veículo jornalístico. Por fim, buscou-se mostrar como os critérios de noticiabilidade e a seleção noticiosa adotados pelo jornal contribuíram para a construção jornalística dos movimentos sociais em questão. Conforme Antunes (2009, p. 87), o jornalista, ao identificar um evento noticiável, mobiliza "uma cadeia de percepções, que vão do repertório de sua experiência individual até as molduras produzidas à escala da sua comunidade interpretativa profissional e àquelas molduras pré-definidas no âmbito do meio em que trabalha)".

\section{OS ENQUADRAMENTOS DA LUTA PELA TERRA}

\subsection{Guerrilha de Porecatu}

A Guerrilha do Porecatu começou com o desejo do então interventor do estado, Manoel Ribas, de povoar 120 mil hectares de terras devolutas na região de Porecatu, Jaguapitã e Centenário do Sul, no norte do Paraná. Através do Departamento de Terras, o governo determinou que iria ceder os lotes a quem derrubasse a mata, plantasse, pagasse impostos e vivesse no local por pelo menos seis anos. O resultado foi uma corrida desordenada ao quase desconhecido sertão paranaense no início da década de 1940, principalmente entre os anos de 1941 e 1943.

Em 1947, o então governador do estado, Moisés Lupion, distribuiu terras a empresários e parceiros políticos. Porém, muitas delas já estavam ocupadas pelos posseiros. O interesse de Lupion era, segundo Oikawa (2011), agradar seus correligionários em troca de apoio político. O próprio governador era acusado de ser dono de uma companhia de terras. A colonização na região virou um verdadeiro balcão de negócios.

Os conflitos armados tiveram início no final de 1948 e só foram desmobilizados em julho de 1951, com a presença da Polícia Militar do Estado e de agentes das Delegacias Especializadas de Ordem Política e Social (DOPS) de São Paulo e do Paraná. Com a anuência e também omissão do poder público, a situação se agravou. O saldo de mortos no combate é incerto (PRIORI, 2012). O historiador Ângelo Priori estima que pelo menos 20 pessoas morreram nos enfrentamentos, sendo 12 jagunços.

Das 29 reportagens publicadas pela Gazeta do Povo em 1951 acerca dos acontecimentos envolvendo a Guerrilha de Porecatu, nenhuma teve como foco indivíduos e 
grupos afetados pelo conflito. Esse dado sinaliza que o jornal optou por não mostrar fatos que pudessem fazer com que a sociedade tivesse ciência a respeito de quem eram e como viviam os cidadãos afetados pela Guerrilha de Porecatu. A partir desta constatação, pode-se destacar os acordos mútuos estabelecidos entre editores, chefes e repórteres que provocaram uma espécie de "cegueira social" a respeito dos posseiros. As autoras Ashley e Olson (1998) apontam justamente que um dos efeitos mais poderosos da mídia é definir a forma com que os fatos serão transmitidos ao público. Escolhendo o que enfatizar, os meios acabam por organizar parte do mundo político para a população.

A reportagem "Levante Comunista no Norte do Estado", publicada na página 8 do dia 14 de junho de 1951, afirma que

30 soldados armados com bombas de gás lacrimogêneo, metralhadoras partiram [...] com destino a Londrina e Porecatu a fim de dar combate à horda comunista que tenta subelevar as populações rurais alegando que estão sendo espoliados pelo governo do Estado. [...] Os vermelhos usam metralhadora e adotam a mesma tática de guerrilha.

Segundo a matéria, a situação na região é gravíssima devido aos "erros da comissão nomeada pelo governo para a redistribuição de terras de vários municípios do Norte". No trecho destacado, que narra a ida da força policial para a região onde ocorria a Guerrilha de Porecatu, é possível perceber duas características relacionadas à forma como o jornal construiu e enquadrou tal episódio histórico. O primeiro que merece registro corresponde à angulação dos fatos. Integrantes da Polícia Militar são apresentados como os "heróis" que irão combater aqueles que estão provocando o caos na região, já que esses indivíduos estariam recrutando populações rurais para ingressarem na "guerrilha".

Esse processo de angulação jornalística está umbilicalmente relacionado ao preceito formulado por Tuchman (1983), a "trama de facticidade", que aponta que antes de publicar a notícia, o jornalista observa os acontecimentos, selecionando e excluindo os fatos. Neste exemplo, o processo de escolha dos fatos a serem narrados prioriza uma angulação favorável às forças governamentais, representadas pelos policiais. Como explica Alsina (2009, p.185), toda produção informativa pode ser reduzida, basicamente, a dois processos: o de seleção e o de hierarquização dos fatos. "Trata-se de selecionar a informação e de determinar a importância de cada uma das informações, estabelecendo assim, sua hierarquização".

Uma segunda característica que merece atenção são os termos utilizados pelo jornal para se referir aos manifestantes ("bandidos", "horda comunista" e "vermelhos", por exemplo). A seleção das palavras é um elemento de suma importância para o tratamento dado 
ao evento narrado. Usar expressões pejorativas ou difamatórias, como o caso exemplificado, denota a criminalização do movimento pelo veículo noticioso.

A matéria "Ação militar na Coreia Brasileira", escrita pelo jornalista e enviado especial Bacilla Neto, relata a rotina dos conflitos na região de Porecatu e também as ações dos policiais militares na localidade. Em texto escrito em primeira pessoa, o repórter aponta que a "ação comunista, pelo que vimos, é um fato". O jornal não apenas afirma que a região é alvo de uma ação comunista como omite informações. Ao descrever as ações militares, o jornalista apenas aponta que cinco soldados foram mortos. Mas não menciona posseiros assassinados ou feridos. Em outro trecho aponta que há "tensão dos soldados", que estavam tendo uma alimentação precária e dormindo em "más acomodações".

Além disso, o jornalista entrevista José Bilar, um posseiro que luta pela terra e que é descrito como um "revoltado". As palavras "vingança" e "revoltado", mais uma vez, evidenciam uma seletividade de adjetivos e termos que desmoralizam a imagem de quem integra o movimento. Os critérios de noticiabilidade implicam diretamente na seleção da informação. Essa seleção se opera em conjunto de fatos que parecem impossíveis de transmitir a totalidade dos acontecimentos. O resultado desse processo, segundo Charaudeau (2006, p.137), é que a seleção dos fatos "impõe um certo recorte do espaço público e uma certa configuração do acontecimento".

A matéria "Inquietação no Norte do Estado", veiculada no dia 17 de junho, na página 8 , descreve "a atuação irregular da Comissão nomeada para resolver quanto às questões de terra criou perigosa situação na região. [...] A atuação da comissão é do arco da velha”. Em outro trecho a reportagem aponta que a comissão era formada por pessoas "residentes na capital e ignorantes do que ocorria na região". Essa reportagem fornece elementos que indicam que a Gazeta do Povo fazia oposição ao então governador Bento Munhoz da Rocha, adversário político de Moysés Lupion - que era um dos acionistas do jornal. Atacar a Comissão de Terras seria uma forma de atacar Munhoz da Rocha, já que tal comissão foi nomeada pelo próprio governo em abril de 1951 especificamente para analisar os acontecimentos na região de Porecatu. A seletividade dos termos e da própria forma como foi redigida a reportagem denota que essas disputas políticas interferiam na forma como o jornal construía os fatos correspondentes à Guerrilha.

Outra matéria, veiculada no dia 23 de junho sob o título "Os conflitos armados em Porecatu" mostra como os combates estão se desenvolvendo na região e ainda aproveita para denotar uma angulação negativa das ações do governo e também dos posseiros: ao passo que 
a matéria ressalta "os bandos armados [...] são ora caracterizados como instrumentos de insufladores comunistas, ora como intrusos revoltados e ainda como simples bandoleiros", a matéria traz uma nota em que o governador diz que "são as mais tranquilizadoras possíveis as notícias procedentes da região de Porecatu". Através deste texto, o jornal consegue construir a notícia de tal modo que ataca os posseiros e, também, mostra aos leitores que o governador está, minimamente, mal informado ou, ainda, que prefere ocultar a realidade.

Nesse período, o então governador do Paraná, Bento Munhoz da Rocha Neto, sofria oposição da Gazeta do Povo. Como ressalta Oliveira Filha (2004), Moysés Lupion - que esteve no posto de governador até janeiro daquele ano e era opositor de Munhoz da Rocha detinha também 50\% do capital da Gazeta do Povo. O reflexo disso é a postura adotada pelo jornal na cobertura dos eventos de Porecatu, que embora tenha tido como ápice de conflito o ano de 1951, suas causas remontam ao tempo em que Lupion era governador. Nenhuma matéria contextualiza esses fatos. Pelo contrário, o jornal, a fim de não atacar Lupion, aponta que as ações governamentais são insuficientes para estancar a crise de terras e, ao mesmo tempo, critica as ações dos posseiros que estariam "colocando em risco a segurança da localidade e promovendo a subversão" em uma região que Lupion tinha interesses políticos e econômicos. É notório afirmar que a seleção das notícias é subjetiva e depende de vários fatores, como a experiência do profissional, suas expectativas e pontos de vista. Porém, a própria direção da organização jornalística ou os seus donos podem influenciar o peso dos valores-notícia em sua política editorial (TRAQUINA, 2008, p.94).

Merece destaque o fato de que em apenas três das 26 reportagens os posseiros foram mencionados como fontes. Como aponta Sousa (2007), o campo jornalístico é permeável pelas fontes organizadas e institucionalizadas, em especial àquelas que são detentoras de algum tipo de poder - que é o que se observa nas análises da cobertura midiática da Gazeta do Povo em relação a esse episódio histórico.

\subsection{Levante de 1957}

Ao longo da década de 50, os moradores do Sudoeste do Paraná se encontravam em uma encruzilhada. De um lado, companhias de terra os forçavam a comprar os lotes em que já residiam. De outro, havia a garantia do governo federal de que eles detinham a posse das terras. Assim como na guerrilha de Porecatu, jagunços contratados pelas companhias de terra transformaram a região em um palco de violência. O próprio governador Lupion, segundo 
Pegoraro (2007), era acusado de ser dono de uma companhia de terras, a Clevelândia Industrial e Territorial Limitada (Citla). Era a segunda vez que Lupion assumia o governo do estado - a primeira entre 1946 a 1950 e depois entre 1955 e 1959.

Segundo Pegoraro (2007), o grupo familiar e empresarial de Lupion estava inserido em diversas atividades, como extração e industrialização de madeira; fabricação de papel, fósforo e caixas; exportação de produtos, como erva-mate, madeira e minérios; agricultura; pecuária e participação em empresas de comunicação, entre elas a Gazeta do Povo e o jornal O Dia.

Em 1956, a Citla, juntamente com duas outras companhias, Comercial e Apucarana que se tornaram suas concessionárias - teve o caminho livre para poder atuar no Sudoeste paranaense. Um dos primeiros atos foi iniciar as medições de vários lotes da região. Os posseiros que se negassem a comprar a terra que, em tese, já pertencia a eles, sofriam diversos tipos de violência. Lideranças políticas alertavam para não aceitarem as vendas dos lotes, mas os colonos estavam confusos e os posseiros acabaram por se rebelar. Tratava-se de "um grupo de pessoas que vivenciou e partilhou experiências comuns e, a partir disso, sentiu e articulou a identidade de seus interesses entre si contra outros que tinham interesses contrários aos seus" (PEGORARO, 2007, p. 44).

No dia 9 de outubro de 1957 iniciou-se, de fato, o que ficou conhecido como Levante dos Posseiros. Os moradores de Pato Branco que ficaram na cidade organizaram um movimento popular para expulsar as companhias de terra e os posseiros tomaram a sede da prefeitura da cidade. As notícias do levante espalharam-se rapidamente. Em Francisco Beltrão, o médico Walter Pecoits leu um manifesto na rádio e no dia seguinte, dia 10, os colonos também tomaram a cidade. Seis mil posseiros se dirigiram à sede do poder municipal rasgando documentos de quem havia comprado as terras da companhia. A reação em cadeia estendeu-se a outras cidades, como Capanema, Santo Antônio do Sudoeste, Barracão, Verê e Dois Vizinhos. Prefeitos e chefes de polícia chegaram a ser presos pelos posseiros, sendo que muitos ficaram em "prisões domiciliares". Diante da situação, o Exército interviu e obrigou que os jagunços saíssem imediatamente do local. A partir do dia 14 não havia sinal algum das companhias de terra. Somente aos poucos a situação foi se normalizando.

A cobertura referente ao Levante de 1957 realizada pela Gazeta do Povo totalizou 52 matérias. Uma delas é "Voltaram os colonos às suas tarefas pacíficas", publicada na primeira página do dia 28 de setembro. A matéria foca em como estaria o dia-a-dia dos colonos na região Sudoeste do Paraná, abordando que eles estariam retornando às corriqueiras atividades 
agrícolas. Mesmo tendo como alvo as ações dos colonos, a seleção do uso das palavras desta matéria sinaliza, por exemplo, que eles, os agricultores, estariam, até então, envolvidos em atividades perigosas, que não seriam "pacíficas", como traz o título da própria matéria.

Além disso, a seleção da angulação, calcada nos critérios de noticiabilidade adotados pela Gazeta do Povo, também aponta que os fatos registrados na região estariam sendo utilizados para atacar o governador Moysés Lupion, como atesta este trecho da matéria: "Os adversários de sr. Moysés Lupion exploram os fatos, ampliando-os para impressionar as autoridades federais e a opinião pública do país". Aí novamente residem os interesses políticos do próprio meio de comunicação, haja vista que neste período o ex-governador permanecia como acionista da Gazeta do Povo - ou seja, é o valor-notícia sendo baseado pela política editorial do veículo de comunicação.

A matéria do dia 15 de setembro, "Tocaia armada em município do Oeste do Paraná", trata de um suposto ato dos colonos no dia anterior que culminou com seis pessoas mortas. A reportagem, em tom de acusação, afirma que um "bando armado de posseiros foi o responsável por essa tragédia”. A única fonte ouvida foi, mais uma vez, o então chefe de Polícia do Estado, Pinheiro Júnior, que também era um dos diretores da Gazeta do Povo.

Em cinco de outubro, uma matéria chama a atenção novamente para o discurso do oposicionista Othon Mader: "Refutadas na Câmara Federal, as declarações do senador Mader”. O senador oposicionista Othon Mader não é ouvido como fonte, é apenas citado nas reportagens quando fontes favoráveis a Lupion rebatem o seu discurso, como pode ser observado, por exemplo, neste trecho: “O sr. Mário Gomes, do PSD do Paraná, refutando as declarações do senador Othon Mader, leu carta do governador Moysés Lupion. [...] O orador garante que o sr. Moysés Lupion não faz, absolutamente, parte da companhia Clevelândia, ao contrário do que se tem dito".

Esses trechos que dizem respeito a uma briga política entre oposicionistas e governistas denotam o tom político que a Gazeta do Povo adotou para cobrir os eventos no Sudoeste do Paraná. Ao passo que as afirmações da oposição são silenciadas, as defesas de governistas e do próprio Lupion são transcritas e reproduzidas como se fossem a verdade. Afinal, como um meio legitimado, o jornal possui a prerrogativa de não publicar mentiras, como aponta o contrato fiducionário descrito por Alsina (2009). No entanto, a seletividade dos fatos e das angulações noticiosas demonstra qual será o "lado da realidade" que o veículo optará por reproduzir. A institucionalização das ações dos repórteres está relacionada, nestes casos apontados, aos próprios interesses políticos do jornal, que se mostra favorável às ações 
governistas e contrário às ações dos posseiros. Além disso, a avaliação do papel do jornalismo na conformação dos valores hegemônicos pode estar ligada aos atores políticos e econômicos, que teriam suas posições e interesses legitimados. (MIGUEL e BIROLI, 2012).

Em todos os casos mencionados fica explícito que a seletividade das palavras e dos fatos, diretamente ligada a um processo rotineiro e padronizado de produzir notícia, salienta um lado pró-governo em detrimento do movimento social. O jornal optou por explicitar que havia um conflito estabelecido entre oposição e governo e entre governo e movimentos sociais, fazendo com que o poder político do governo paranaense fosse tratado como vítima das ações dos manifestantes e também dos políticos oposicionistas.

Estes exemplos corroboram para o fato de que o uso de determinadas técnicas institucionalizadas dentro das redações contribui para a seleção dos fatos e também para dar a impressão de que o material veiculado cumpre os requisitos da objetividade jornalística. As fontes podem também ser utilizadas e selecionadas de forma com que os jornalistas ou o jornal insiram no texto o que eles próprios pensam sobre determinado acontecimento. A consequência é a construção social de uma realidade produzida de forma institucional, em que a permeabilidade das fontes oficiais se sobressai perante as demais. Tal seletividade das fontes recai, na maior parte das vezes, no fato de o jornalista priorizar as fontes legitimadas institucionalmente e que na maioria das vezes representam determinado interesse. Jorge Pedro Sousa (2007, p.22) ressalta que várias investigações empíricas demonstram que o "campo jornalístico é particularmente permeável às fontes organizadas e sofisticadas de informação, em particular às fontes detentoras de poder”.

\subsection{Movimento Rural Sem Terra}

Oficialmente o Movimento dos Trabalhadores Rurais Sem Terra (MST) foi criado em 1984 na cidade de Cascavel, na região oeste do Paraná, durante o $1^{\circ}$ Encontro Nacional dos Trabalhadores Rurais Sem Terra. Contudo, a semente para o surgimento do MST já existia nos anos anteriores, durante os anos de opressão do regime militar. O $1^{\circ}$ Congresso do MST aconteceu durante os dias 29 a 31 de janeiro de 1985. Segundo o próprio MST, este congresso foi um marco para o movimento. Em maio do mesmo ano, em menos de três dias cerca de 2,5 mil famílias fizeram 12 ocupações no estado de Santa Catarina. Em outubro, houve ocupação no Rio Grande do Sul e, a partir de então, a prática das ocupações de terra ganhou corpo e se espalhou para outros estados. 
Mas é na década de 90, já sob a presidência de Fernando Henrique Cardoso, que um dos episódios mais marcantes do movimento é registrado. Foi nessa época que o país testemunhou os dois maiores massacres da segunda metade do século XX: Corumbiara (1995), em Rondônia, e Eldorado dos Carajás (1996), no Pará.

Desde 1997, o MST se mobiliza em um movimento que ficou conhecido como "Abril Vermelho" - a "Jornada Nacional de Lutas pela Reforma Agrária" tomou como símbolo os massacres e reivindica anualmente a reforma agrária. No Paraná, o cenário não foi diferente e o período em que mais foram registradas ações do movimento foi quando Jaime Lerner era governador do Paraná. Durante o período em que ele governou o estado, entre 1995 a 2002, 16 trabalhadores sem terra foram assassinados - sendo oito no ano de 1998, segundo a Comissão da Pastoral da Terra. Atualmente, o Movimento Sem Terra está organizado em 24 estados nas cinco regiões do país e cerca de 350 mil famílias conquistaram terra devido à ação do movimento.

A pesquisa acerca da cobertura referente ao Movimento dos Trabalhadores Rurais Sem Terra (MST) no ano de 1998, período em que mais foram contabilizadas mortes nos campos paranaenses, resultou 213 matérias sobre o assunto. Nessa época o jornal já pertencia a Francisco da Cunha Pereira Filho e a Edmundo Lemanski.

A matéria do dia 30 de janeiro, publicada na página 40 sob o título "Duas sem terra denunciam acampamento" mostra um conflito interno no próprio movimento, como pode ser demonstrado pela citação a seguir: "As sem terra Rosa Castro dos Santos, 35 anos, e Maristela Gonçalves da Cruz, 23 anos, deixaram no último final de semana o acampamento da Fazenda São Pedro, em Querência do Norte, Noroeste do estado, denunciando irregularidades praticadas pelo MST". No texto, elas alegam que os integrantes do acampamento "retêm os documentos pessoais" e "entre as demais denúncias estão que nenhuma criança do acampamento vai para a escola”. Segundo a publicação, o MST rebate a afirmação através de entrevista com o então coordenador estadual do movimento, Nildemar da Silva, que afirma que as denúncias não procedem e são levianas.

Esse exemplo aponta para uma estratégia que tende a criminalizar o movimento. Ashley e Olsen (1998) ressaltam que os meios de comunicação podem moldar um grupo de um movimento social de diversas maneiras: inviabilizando-o pela descrição dada ao manifestante; relatando os acontecimentos ao invés dos objetivos e interesses do grupo; ou marginalizando pontos de vista atribuindo-os a um desviante social. Elas também apontam que outra prática utilizada pelos meios de comunicação é publicar brigas internas como forma 
de deslegitimar o movimento: "Groups are shown as illegitimate when quotation marks are used to trivialize and make light of movement language, appearance of protesters is included, protesters are undercounted, and internal dissension is emphasized"33 (1998, p.265).

No presente exemplo, explicita-se que o jornal priorizou um fato isolado em detrimento dos objetivos de todo grupo, passando ao público leitor uma visão deturpada e negativa do movimento. Isso ocorre pela seleção das angulações da notícia adotados no processo rotineiro do jornal a partir dos valores-notícia.

No dia 20 de fevereiro a reportagem "Sem terra é baleado durante desocupação de fazenda" mostra a ação de desocupação de 220 pessoas de duas fazendas ocupadas pelo movimento. A situação acabou em conflito contra os 399 policiais militares e civis que participaram do ato: "Em uma das áreas desocupadas, a Fazenda Esperança, em Mamborê, (...) o sem terra José Fausto dos Santos, de 36, anos foi baleado na barriga". A informação oficial da Secretaria Estadual de Segurança Pública, segundo a reportagem, era a de que "Santos é fugitivo da Justiça".

Neste exemplo pode ser constatado que o jornal procurou relatar os fatos norteados pelo discurso da objetividade. Ainda que não culpe diretamente o MST pelos atos de violência, a Gazeta do Povo seleciona e narra os fatos demonstrando que as ocupações das fazendas proporcionadas pelo movimento seriam as causas dos conflitos.

A seleção das fontes inclui os relatos dos responsáveis pelos acampamentos daqueles que lutam pelo direito à terra. Também nota-se o uso de aspas como uma das estratégias adotadas no processo rotineiro para transmitir ao leitor uma visão imparcial do jornal. Outra matéria é a do dia $1^{\circ}$ de julho, que evidenciou a relação conflituosa entre a UDR e o MST. Sob o título "Tensão entre sem terra e UDR", o texto coloca os dois como adversários um do outro, além de usar palavras como "tensão" e "denúncias" que reforçam a ideia de conflito entre os lados envolvidos.

Novamente, assim como percebido na análise dos movimentos anteriores, a seleção das palavras exerce papel fundamental para que a situação narrada influencie na transmissão dos fatos e, consequentemente, na sua construção social. Além disso, percebe-se que os valores-notícia, intrinsicamente relacionados ao processo das rotinas de produção do

3 Os grupos são mostrados como ilegítimos quando as aspas são usadas para trivializar a linguagem de movimento, a aparência dos manifestantes é incluída, os manifestantes são subestimados, e a dissensão interna é enfatizada. (tradução própria). 
jornalismo, são calcados pela proeminência do frame conflito quando o assunto é o MST. Como apontam Miguel e Biroli (2012, p.25) mesmo que outros recortes sejam possíveis, "aquele que o jornalismo apresenta é o que se impõe como importante, tanto por seu impacto junto ao público quanto porque os jornalistas não vacilam na crença de que são dotados da capacidade de selecionar os fatos verdadeiramente dignos de relato".

Dessa maneira, pode-se aferir que a seletividade das angulações e dos fatos a serem noticiados pela Gazeta do Povo prioriza tratar o movimento como protagonista em provocar discórdias e perturbar a ordem da localidade, incentivando uma visão negativa da população acerca das reivindicações do MST - consequentemente há a tendência em criminalizar o movimento, como mencionado anteriormente. Ou seja, o discurso jornalístico acaba sendo validado por um senso comum que o próprio jornalismo contribui para formatar (MIGUEL e BIROLI, 2012).

Ao longo de toda cobertura, no entanto, integrantes do MST também foram fontes ouvidas pela reportagem. Em todas as reportagens analisadas percebeu-se que mesmo que o tom da matéria pudesse trazer impactos negativos ao movimento, a prerrogativa dos jornalistas era ouvir algum integrante do MST. Essa lógica está arraigada ao mito da objetividade, em que o jornal precisa transmitir um acontecimento com o máximo de isenção possível.

Para isso, a rotina de produção também traz o uso frequente das aspas, presente em todas as reportagens. Essas duas características - a pluralidade e o fato de transcrever afirmações dos entrevistados - tendem a passar a impressão de isenção. Contudo, ao priorizar o ingresso de determinadas fontes mais poderosas nas notícias os jornalistas assumem o risco de fazer com que as notícias ceguem a realidade social. Segundo Tuchman (1983, p.227), "los métodos de identificar a las fuentes apropriadas, objetivan a la vida social $\mathrm{y}$, a veces, reifican a los fenómenos sociales".

A autora (1983, p.109) explica que o uso das aspas é uma forma de tentar mostrar que o jornalista está distante e neutro em relação ao fato relatado, "repassando" a outros o direito de expressar as opiniões. No entanto, elas podem muito bem ser utilizadas e selecionadas de forma com que os jornalistas insiram no texto o que eles próprios pensam sobre determinado acontecimento: "Las comillas hacen más que quitar la voz del reportero de un relato y señalar que 'esta declaración' pertence a una persona distinta que el reportero".

Portanto, a seleção das aspas, das fontes e da angulação dos fatos influencia diretamente em como esses fatos serão transmitidos à sociedade. Além disso, a seleção dos 
assuntos abordados pelo jornal também impede que a totalidade dos fatos seja publicada - há um recorte dos fatos que ganharão espaço no jornal.

\section{CONSIDERAÇÕES}

A análise da cobertura da Gazeta do Povo sobre os três movimentos - Guerrilha de Porecatu, Levante de 1957 e MST - permite constatar diferenças e semelhanças na produção jornalística. Se na cobertura acerca de Porecatu o jornal se referia aos manifestantes através de palavras e expressões pejorativas de forma explícita, como "vermelhos" e "bandidos", essa postura não se repete nem na cobertura do Levante dos Posseiros e nem na do MST. No entanto, a seleção das palavras que dão o tom do enquadramento adotado pelo jornal permaneceu durante os três momentos.

Se o jornal não usou mais a expressão "bandidos" para se referir ao MST optou por utilizar a expressão "invasores", que dá a conotação de que estariam praticando algo não só ilegal, mas também injusto. O mesmo ocorre ao tratar os posseiros da região sudoeste, quando aponta que os manifestantes voltaram "às atividades pacíficas", isto é, até então esses manifestantes estavam provocando transtornos e atos de violência, segundo o jornal.

A seletividade das palavras e das angulações dos fatos também está presente nos três momentos analisados. Percebe-se que a angulação favorável ao governo permanece ora de maneira mais explícita como nos dois primeiros movimentos, ora de maneira mais implícita, no caso do MST. Esse resultado era esperado devido à distância histórica entre cada um dos movimentos. Durante as cerca de quatro décadas que afastam os dois primeiros movimentos do terceiro o jornalismo passou por mudanças.

Nesta fase, as empresas jornalísticas transformavam-se gradativamente em empresas economicamente consolidadas. As técnicas do jornalismo norte-americano, uso do lead e da pirâmide invertida, chegavam ao Brasil. De 1945 a 1964 os jornais brasileiros foram se adaptando a essas mudanças. Na presente análise, percebe-se que na cobertura sobre a Guerrilha de Porecatu não havia o uso do lead. Já nas reportagens a respeito do Levante de 1957 essa técnica surge em alguns momentos e na cobertura do MST é raro encontrar uma reportagem que não a contenha.

Pode-se constatar que a produção jornalística apresentou mudanças no decorrer das décadas. Essa evolução no modo de se fazer jornalismo no Brasil, contudo, não foi capaz de afastar os interesses editoriais dos meios de comunicação. A própria seleção das fontes 
fornece pistas sobre esta constatação. Ao passo que nas duas primeiras análises constata-se que vozes discordantes do governo não estavam inseridas diretamente nas reportagens, a cobertura acerca do MST procurou dar voz aos integrantes do movimento. Essa, inclusive, é uma das características apontadas para que o jornal possa, novamente, transmitir uma ideia de isenção. Escutar o outro lado indica que pelo menos o veículo procurou mostrar a visão do MST. No entanto, sabe-se que a seleção do que é falado pela fonte é responsabilidade do jornalista e, além disso, a seleção de como tal fato será abordado passa pelo crivo do jornal. Isso pode resultar em omissões de dados ou afirmações que tendem a transmitir uma visão parcial dos fatos.

Deste modo, a criminalização dos movimentos sociais permanece sendo transmitida ao público leitor. Sabe-se que os meios de comunicação desempenham um papel crucial na repercussão dos movimentos sociais. Ao decidir transmitir as notícias por determinada angulação ou priorizando determinadas fontes jornalísticas, os veículos podem passar diferentes mensagens para o público. De acordo com Miguel e Biroli (2012, p.23), a busca e os obstáculos pela chamada "objetividade jornalística" perpassam pelas "condições concretas de construção da notícia". Os “fatos 'objetivos' e julgamentos complementam-se na legitimação do jornalismo como guardião dos valores sociais", afirmam os autores (p.42). Essa dinâmica está inserida nas práticas e rotinas adotadas pelos veículos jornalísticos contemporâneos.

Isso corresponde, portanto, aos critérios adotados para a angulação do tema, a seletividade das fontes e das aspas e a abordagem jornalística em relação à cobertura a ser adotada acerca dos movimentos sociais. O processo de construção da notícia gera um ponto de vista específico do fato narrado à parcela da sociedade e este ponto de vista passa a ser considerado como "verdadeiro". A importância dessa reflexão recai na própria forma como essa história será narrada para as futuras gerações. Como apontam Leal e Antunes (2015) todo o texto testemunhal é um fragmento de condições históricas. Afinal, a atualidade do jornalismo não o afasta de uma produção histórica, já que como afirma Antunes (2007), o "transitório e o descontínuo compõem toda duração histórica".

O impacto de historicidade dos meios de comunicação não se limita, portanto, apenas ao momento presente - haverá reflexos em como essas histórias foram, são e serão vistas aos olhos do cidadão comum.

\section{REFERÊNCIAS}


ANTUNES, Elton. Enquadramento: considerações em torno de perspectivas temporais para a notícia. Revista Galáxia, São Paulo, n. 18, p.85-99, dez. 2009.

Temporalidade e produção do acontecimento jornalístico. Em Questão, volume $13, \mathrm{n}^{\circ} 1,2007$.

ALSINA, Miguel Rodrigo. A construção da notícia. Petrópolis: Editora Vozes, 2009.

ASHLEY, Laura; OLSEN, Beth. Constructing Reality: printes media framing of the women 1966 to 1986. IN: JeMC Quarterly, vol. 75, nº 2 Summer, 1998.

BERGER, Peter L.; LUCKMAN, Thomas. A construção social da realidade. Petrópolis: Editora Vozes, 36. ${ }^{\mathrm{a}}$ edição, 2014.

CARVALHO, Carlos Alberto. O enquadramento como conceito desafiador à compreensão do jornalismo. Anais XIV Congresso de Ciências da Comunicação na Região Sudeste, 2009.

CHARAUDEAU, Patrick. Discurso das mídias. São Paulo: Contexto, 2. a edição, 2012.

LEAL, B.S.; ANTUNES, E. (2015). O testemunho midiático como figura de historicidade: implicações teórico-metodológicas. Chasqui. Revista Latinoamericana de Comunicación, No129 (2015). Pp. 213-228.

MIGUEL, Luis Felipe; BIROLI, Flávia. Orgulho e preconceito: a "objetividade" como mediadora entre o jornalismo e seu público. IN: Revista Opinião Pública, Campinas, vol. 18, $\mathrm{n}^{\circ} 1$, Junho, 2012.

MOVIMENTO DOS TRABALHADORES RURAIS SEM TERRA. Nossa História. Disponível em http://www.mst.org.br/nossa-historia.

OIKAWA, Marcelo. Porecatu: a guerrilha que os comunistas esqueceram. São Paulo: Expressão Popular, 2011.

OLIVEIRA FILHA, Elza Aparecida de. Apontamentos sobre a história de dois jornais curitibanos: "Gazeta do Povo" e "O Estado do Paraná". In: Cadernos da Escola de Comunicação UniBrasil. Volume 1, número 2, 2004.

PEGORARO, Éverly. Dizeres em confronto: a Revolta dos Posseiros de 1957 na imprensa paranaense. Dissertação (Mestrado em História Social). Universidade Federal Fluminense, Niterói, 2007.

Revolta dos posseiros de 1957: consensos e desacordos de algumas interpretações. Revista Ideas - Interfaces em Desenvolvimento, Agricultura e Sociedade, Rio de Janeiro, v. 2, n.1, p. 109-133, jan.-jun. 2008.

PRIORI, A., et al. História do Paraná: séculos XIX e XX [online]. Maringá: Eduem, 2012. A revolta camponesa de Porecatu. pp. 129-141. ISBN 978-85-7628-587-8. 
RIBEIRO, Ana Paula Goulart; BRASILIENSE, Danielle Ramos. Memória e narrativa jornalística. IN: RIBEIRO, Ana Paula Goulart; FERREIRA, Lucia Maria Alves(orgs). Mídia e memória: a produção de sentidos nos meios de comunicação. Rio de Janeiro: Mauad X, 2007.

SOUSA, Jorge Pedro. A teoria do agendamento e as responsabilidades do jornalista ambiental: uma perspectiva ibérica. IN: Revista Eletrônica da Biblioteca On-line em Comunicação (www.bocc.pt). Portugal, 2007.

. Elementos de Teoria e Pesquisa da Comunicação e dos Media. Porto: $2^{\mathrm{a}}$ edição revista e ampliada, 2006.

TRAQUINA, Nelson. Teorias do Jornalismo - volume 2 - A tribo jornalística: uma comunidade interpretativa transnacional. Florianópolis: Editora Insular, 2008.

TUCHMAN, Gaye. La producción de la noticia: estudio sobre la construcción de la realidad. Barcelona: Gili, 1983.

A objectividade como ritual estratégico: uma análise das noções da objectividade dos jornalistas. In: TRAQUINA, N. (org.) Jornalismo: questões, teorias e estórias. Vega, 1993

As notícias como uma realidade construída. In: ESTEVES, J. P. Comunicação e Sociedade: Os efeitos sociais dos meios de comunicação de massa. Lisboa: Livros Horizonte, 2002.

Original recebido em: 27 de outubro de 2017

Aceito para publicação em: 26 de julho de 2019

Carla Candida Rizzotto

Doutora em Comunicação pela Universidade Tuiuti do Paraná (UTP). Professora e pesquisadora do Programa de Pós-Graduação em Comunicação e do Departamento de Comunicação da Universidade Federal do Paraná (UFPR).

Diego Antonelli

Mestre pelo Programa de Pós Graduação em Comunicação da Universidade Federal do Paraná (UFPR). Autor dos livros Em Domínio Russo (2009), Paraná: Uma História (2016) e Vindas:

Memórias da Imigração (2018).

\section{(2) $(\Theta \odot$}

Esta obra está licenciado com uma Licença

Creative Commons Atribuição-NãoComercial-CompartilhaIgual 4.0 Internacional 